\title{
Estudo comparativo sobre a formação de professores de música em Portugal e no Brasil
}

\author{
Graça Mota* \\ Sergio Figueiredo**
}

\section{Resumo}

A formação de professores de música em Portugal e no Brasil é o foco deste texto, que tem por objetivo apresentar aspectos preliminares de um estudo que vem sendo realizado a partir de contextos de Ensino Superior nos dois países. Com inspiração na metodologia da educação comparada, o presente estudo vem investigando documentos oficiais e currículos para promover a reflexão comparativa sobre diferentes caminhos oferecidos em Portugal e no Brasil para a preparação de professores de música, com ênfase na educação escolar. A formação de professores de música nos dois países foi pontualmente analisada a partir dos seguintes elementos: contexto educacional em Portugal e no Brasil; preparação musical anterior ao Ensino Superior e os critérios de ingresso nos cursos de formação de professores de música; elementos curriculares dos cursos formadores; prática docente e perspectivas profissionais. Os resultados preliminares desta análise comparativa demonstram semelhanças e diferenças nos dois contextos: 1) professores de música para a educação escolar são formados em instituições de Ensino Superior nos dois países, sendo que em Portugal, além da licenciatura em música, é exigida a formação em nível de mestrado profissionalizante; 2) em ambos os países são realizadas provas específicas de ingresso nas instituições, exigindo conhecimentos musicais prévios; 3 ) o equilíbrio entre a formação musical e pedagógica é um dos objetivos curriculares; 4) a prática docente é componente enfatizado na formação de professores; 5) em Portugal a motivação para a atuação na escola regular é maior do que no Brasil.

Palavras-chave: formação de professores de música, currículos universitários, prática docente.

\footnotetext{
* Professora Ph.D. Coordenadora - Unidade Técnico-Científica de Música, Coordenadora do Centro de Investigação em Psicologia da Música e Educação Musical (Cipem). Escola Superior de Educação, Instituto Politécnico do Porto, Portugal.

** Professor Doutor da Universidade do Estado de Santa Catarina (Udesc), Florianópolis, Santa Catarina Brasil.
} 
Graça Mota - Sergio Figueiredo

\section{A comparative study on music teacher preparation in Portugal and Brazil}

Abstract

The preparation of music teachers in Portugal and Brazil is the focus of this text, which aims at presenting preliminary aspects of a study in progress in the context of higher education in both countries. Inspired by comparative education methodology, the present study is investigating official documents and academic curricula offered in Portugal and Brazil for the music teachers' preparation to promote, in different ways, the comparative reflection with an emphasis on school education. The music teachers' education in both countries was analyzed taking into account the following elements: educational context in Portugal and Brazil; music preparation prior to higher education, and the entrance criteria in the courses that are offered for music teachers; curricular elements of the courses; teaching practice and professional perspectives. The preliminary results of this comparative analysis demonstrate similarities and differences in the two contexts: 1) in both countries, music teachers for regular schools receive their degrees in higher education institutions, and in Portugal, beyond the Licenciatura in Music, a Music Education Master degree is demanded; 2) in both countries specific entrance tests are accomplished in the universities, demanding previous musical knowledge; 3 ) the balance among the musical and pedagogical preparation is one of the curricular objectives; 4) the teaching practice is an emphasized component in the teachers' preparation; 5) in Portugal, student's motivation for the work in the regular school appears to be larger than in Brazil.

Keywords: music teacher preparation, higher education curricula, teaching practice.

\section{Introdução}

A formação de professores tem sido um grande desafio para a educação em vários países. Com novas demandas impostas pelas rápidas mudanças na sociedade contemporânea, novas reflexões são obrigatórias para a formação daqueles que serão responsáveis pela educação na escola e em outros espaços sociais.

Se a educação é parte de um continuum que se transforma constantemente, adaptando-se - ou não - às necessidades dos mais variados contextos, a formação de professores também é parte indissociável deste processo. Formar professores de música, portanto, também se insere nos desafios da educação contemporânea, com o principal objetivo de tornar estes profissionais cada vez mais competentes como educadores.

As instituições que formam professores assumem continuamente a alteração de seus currículos, compreendendo a necessidade de oferecer aos 
estudantes a preparação adequada para a atuação em diversos espaços educativos. Este processo de mudança curricular exige avaliação contínua baseada na atualização legal, na atualização bibliográfica e no feedback dos próprios estudantes que trazem os resultados de suas experiências durante sua formação universitária.

A atualização bibliográfica inclui, obrigatoriamente, o contato com experiências em diferentes contextos educacionais, nos quais soluções específicas são buscadas para atender as necessidades locais. Isto quer dizer que podemos aprender estudando a experiência do outro, não para copiá-la, e sim, para ampliarmos nossas capacidades reflexivas acerca do processo da formação do professor.

Assim, este texto apresenta uma breve discussão a partir de um estudo maior que vem sendo realizado sobre a formação de professores de música em Portugal e no Brasil. O principal interesse está na reflexão sobre diferentes caminhos oferecidos nestes dois países com relação à preparação para o ensino de música, com ênfase na educação escolar.

\section{Elementos de educação comparada}

Este estudo inspira-se na perspectiva metodológica da educação comparada, considerando que as reflexões advindas da comparação em educação "possibilitam subsídios teóricos para conhecer e experienciar diferentes sistemas de ensino e realidades educativas" (MARCONDES, 2005, p. 141). Conhecer e comparar o que tem sido utilizado como referência para as decisões curriculares sobre formação de professores em diferentes contextos pode trazer novas compreensões para que se definam novas intervenções neste processo.

Nóvoa e Catani (2000) destacam a necessidade de problematizar o próprio sentido da comparação para que se possa "criar categorias férteis na apreensão das peculiaridades dos processos de apropriação dos saberes e da invenção das práticas no campo educacional" (p.1). Neste sentido, a comparação pretende ampliar perspectivas trazendo aquilo que poderia ser significativo a partir das análises realizadas. Não se pretende comparar para definir o que é melhor, ou que é mais correto, mas sim, para dialogar com diferentes perspectivas, diferentes modos de pensar e agir em educação.

As palavras de Ferreira (2008) sintetizam o processo metodológico empregado neste estudo.

Quando rigorosamente efectuada, a leitura dos aspectos comuns e das diferenças relativas a uma problemática fornecem informações mais interessantes que as resultantes de uma leitura dessa mesma problemática num só contexto. A comparação em educação gera uma dinâmica de raciocínio que obriga a identificar seme- 
Graça Mota - Sergio Figueiredo

\begin{abstract}
Ihanças e diferenças entre dois ou mais factos, fenómenos ou processos educativos e a interpretá-las levando em consideração a relação destes com o contexto social, político, económico, cultural, etc. a que pertencem. (FERREIRA, 2008, p. 125)
\end{abstract}

Assim sendo, a formação de professores de música em Portugal e no Brasil foi pontualmente analisada a partir dos seguintes elementos: contexto educacional em Portugal e no Brasil; preparação musical anterior ao Ensino Superior e os critérios de ingresso nos cursos de formação de professores de música; elementos curriculares dos cursos formadores; prática docente na formação do professor de música e perspectivas profissionais.

\title{
Contexto educacional português
}

A formação de professores de música em Portugal tem uma história relativamente recente. Para efeitos de uma melhor compreensão das questões que se colocaram a partir do início dos anos oitenta do século passado, será apresentada uma introdução breve acerca do sistema educativo português e de como se chegou à formação de professores de educação musical para o chamado ensino não vocacional e no atual quadro do denominado processo de Bolonha.

Até a publicação do Decreto-Lei n. 310/83 (PORTUGAL, 1983), todos os profissionais de música faziam a sua formação nos conservatórios e academias de música sendo o diploma final de composição, canto ou instrumento, considerado de nível superior. Com a publicação do referido decreto, foi estabelecida uma divisão entre ensino secundário de música, a ser ministrado nos conservatórios e academias, e Ensino Superior de música, a ser ministrado nas então criadas escolas superiores de música e escolas superiores de educação dos institutos politécnicos, bem como nas universidades, sendo estes os dois subsistemas que constituem o Ensino Superior em Portugal. Com a abertura das escolas superiores de educação (ESE) no ano de 1986, pela primeira vez em Portugal, se encetou um processo irreversível no âmbito da formação de professores de educação musical para o ensino básico (EB) consignado num perfil de licenciatura de 4 anos: o curso de professores do ensino básico (EB)/ variante de educação musical (professor generalista para o $1^{\circ}$ ciclo do EB e especialista para o $2^{\circ}$ ciclo do EB).

Convém aqui explicitar que o sistema educativo português contempla três ciclos, respectivamente o $1^{\circ}$ ciclo do Ensino Básico (EB) de 4 anos (6-9), o $2^{\circ}$ ciclo do EB de 2 anos (10-11) e o $3^{\circ}$ ciclo do EB de 3 anos (12-14). A este conjunto de 9 anos de escolaridade básica acresce o Ensino Secundário de 3 anos num total de 12 anos, que se constitui como a base de entrada para as universidades e politécnicos. 
A presença do ensino da educação musical no Ensino Básico é irregular e vem perpetuando constantes ambiguidades e zonas pouco definidas e assumidas, quer do ponto de vista do recrutamento de docentes, quer da sua relevância no âmbito do currículo geral (MOTA, 2001; 2003).

No 1ํciclo do EB a música está atualmente apenas presente enquanto atividade de enriquecimento curricular, de carácter não obrigatório. Com a publicação do Despacho 12591/2006 (PORTUGAL, 2006) que regulamenta estas atividades, confirmaram-se as piores expectativas no que diz respeito ao debate que os educadores musicais vinham travando no sentido de apostar numa docência coadjuvada - professor generalista e professor especialista - ao nível da educação musical no $1^{\circ}$ ciclo do $\mathrm{EB}$, aliás consignada na Lei de Bases do Sistema Educativo Português (PORTUGAL, 1986) no seu artigo 8‥ Pelo contrário, e após mais de vinte anos de formação de professores de educação musical, os formadores para estas atividades passam a poder ser recrutados de novo diretamente dos conservatórios, escolas e academias de música, hoje Ensino Secundário de Música. Todo o programa foi levado para o terreno sem qualquer estudo piloto que permitisse aferir a sua exequibilidade no sentido de encontrar a melhor forma de pôr em prática uma desejável colaboração dos professores generalistas em todo o processo da sua implementação. Dado que este programa depende diretamente das autarquias locais, assiste-se a situações muito díspares, já que dependem essencialmente do tipo de agentes que as promovem, da valoração que the atribuem e também do significado político que daí pode advir (MOTA, 2007).

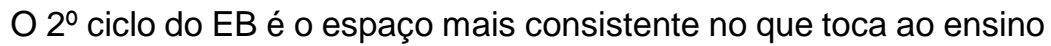
da educação musical. Com um espaço curricular bem definido em paridade com todas as outras áreas do currículo, os alunos têm acesso a dois anos de formação nesta área com um professor especialista o qual tem vindo a ganhar espaço de intervenção e dignidade em tudo semelhante a dos seus pares responsáveis pelas outras áreas do saber. Finalmente, no $3^{\circ}$ ciclo do EB a música surge em algumas escolas como oferta muito irregular e sempre sujeita à existência de um professor de educação musical com capacidade e horário disponível para levar a cabo essa tarefa.

Para efeitos deste trabalho, o foco principal incidirá sobre a formação de professores de educação musical para o EB (6-14), ensino não vocacional de música, com um enfoque nos atuais currículos que advêm da integração plena desde 2010 do Ensino Superior português no sistema de Ensino Superior europeu, conhecido como processo de Bolonha.

\section{O advento do processo de Bolonha em Portugal}

A Declaração de Bolonha (ou declaração conjunta dos ministros europeus da educação pertencentes ao Espaço Europeu de Ensino Superior) foi assinada a partir de um encontro que teve lugar em Bolonha, Itália, em 19 de 
junho de 1999 (DECLARAÇÃO DE BOLONHA, 1999). Aí se define o ano de 2010 como data uniformizadora para a construção de uma área competitiva, a concretizar através da promoção da mobilidade e empregabilidade no espaço europeu. Para atingir esta meta, foram definidos objetivos específicos que relevam uma necessidade de comparabilidade de graus acadêmicos, nomeadamente através da introdução de três ciclos de estudos no Ensino Superior (licenciatura, mestrado e doutoramento), a promoção da mobilidade de estudantes e professores, tendo em vista a cooperação para o estabelecimento de padrões de qualidade, e o desenvolvimento de uma dimensão europeia em termos institucionais.

No que diz respeito à formação de professores, a grande mudança ficou consignada na obrigatoriedade da obtenção do grau de mestre para a docência em todos os graus do ensino não superior, incluindo a Educação de Infância. As escolas superiores de educação passaram, assim, a oferecer dois perfis de formação: a licenciatura de três anos numa área específica do saber, e o mestrado profissionalizante de dois anos para o exercício da docência. Assim, a possibilidade de acesso à profissão docente está atualmente vinculada à obtenção do grau de licenciatura acrescido do mestrado profissionalizante.

\section{$1^{\circ}$ ciclo de estudos superiores - a licenciatura em Portugal}

A estruturação da nova licenciatura em educação musical foi pensada no sentido de conjugar uma formação científica de elevada qualidade no âmbito da educação musical, sem perder de vista a criação de um perfil profissional que pudesse dar resposta ao trabalho em contextos em que a música se constitui como eixo estruturante do desenvolvimento humano numa perspectiva não vocacional, ou seja, o que se convencionou chamar de técnico de educação musical com capacidade para intervir em contextos formais e não formais, nomeadamente no âmbito das actividades de enriquecimento curricular no $1^{\circ}$ ciclo do EB. Privilegia-se igualmente a construção de projectos que promovam uma prática artística integrada, atribuindo uma relevância formativa e educativa às práticas socioculturais e artísticas da comunidade envolvida, desenvolvendo-as e enquadrando-as de forma social, científica, cultural e ética.

Em forma de exemplo, já que os currículos diferem de instituição para instituição, a ESE do Porto oferece uma licenciatura que contempla três áreas estruturantes ao longo dos seis semestres que a constituem: formação musical, prática instrumental e vocal e ciências musicais. Inclui uma componente relevante na área de português na perspectiva, por um lado, da utilização competente da língua materna e, por outro, das relações entre esta e as áreas artísticas. Apresenta ainda formação geral em educação, em pedagogia musical, em informática musical, inglês, educação especial, expressão dramática e educação visual (oficina de artes). É de notar que as duas últimas justificam um perfil profissional mais abrangente do ponto de vista artístico, o qual se concretiza na área de projectos a realizar no primeiro e segundo 
ano do curso e que convocará, para além daquelas, a própria música e a área de português.

Pretendeu-se com esta licenciatura, por um lado, proporcionar uma formação musical suficientemente diversificada para permitir o ingresso em múltiplas atividades ligadas à música e à criação artística e, por outro, constituir-se como a formação de base adequada para todos os que pretendam prosseguir estudos ao nível de mestrado profissionalizante para o ensino da educação musical no EB.

O ingresso neste curso processa-se através de uma prova de prérequisitos obrigatória que pressupõe que todos os candidatos tenham adquirido previamente à sua entrada no Ensino Superior uma formação musical abrangente, incluindo o domínio, a um nível razoável, de um instrumento ou canto. A obrigatoriedade de realização desta prova tem sido objeto por parte dos responsáveis por estes cursos nas ESE de um debate alargado que não poderá nunca ser dado como concluído. Por um lado admite-se que esta obrigatoriedade reafirma a necessidade de uma formação musical prévia ao ingresso no Ensino Superior (e muitas vezes a expensas próprias) e que tal pode ser considerado em Portugal como um elemento de exclusão dada a precária formação musical que é oferecida na escola pública. Por outro lado, parece ser do domínio do impossível formar um músico capaz de intervir em vários contextos educativos, mesmo que não formais, sem que uma base musical tenha sido obtida antes do ingresso no Ensino Superior.

\section{0 ciclo de estudos superiores - o mestrado profissionalizante em Portu- gal}

No quadro da formação de acordo com o modelo de Bolonha, a estruturação de um $2^{\circ}$ ciclo de estudos de caráter profissionalizante partiu do pressuposto da existência de uma formação científica de elevada qualidade no âmbito da educação musical, anteriormente adquirida ao nível da licenciatura.

Nesse sentido, o currículo do $2^{\circ}$ ciclo de estudos, mestrado em ensino de educação musical no EB, contempla as seguintes áreas científicas estruturantes ao longo de quatro semestres: ciências da educação, metodologia e didáctica da educação musical, música, práticas educativas e supervisão pedagógica. Tem como grande finalidade criar um perfil de docente capaz de intervir como professor das disciplinas de educação musical dos $2^{\circ}$ e $3^{\circ}$ ciclos do Ensino Básico e de dar apoio especializado à concretização do programa de educação musical no âmbito do regime de monodocência do $1^{\circ}$ ciclo do EB.

De acordo com a grande finalidade já expressa, $02^{\circ}$ ciclo de estudos visa formar um professor de educação musical com as seguintes competências: 


\section{Graça Mota - Sergio Figueiredo}

- no $1^{\circ}$ ciclo do EB - promover a integração da música no modelo de monodocência, dando apoio ao professor do $1^{\circ}$ ciclo, quer no ensino de "expressão e educação musical", quer na organização de projetos musicais e artísticos no âmbito da escola em que intervém;

- no $2^{\circ}$ ciclo do EB - promover a gestão do currículo a partir dos domínios da audição, da interpretação e da composição enquadrando-os nas diferentes épocas e estilos ao longo da história da música, numa perspectiva integradora e no respeito pela diversidade cultural que caracteriza a escola de hoje;

- no $3^{\circ}$ ciclo do EB - desenvolver e alargar as competências anteriormente expressas para o $2^{\circ}$ ciclo do EB, numa perspectiva aprofundada da história da música, da acústica e da organologia e dinamizar e dirigir grupos instrumentais e vocais no âmbito do currículo e da comunidade escolar.

\section{Contexto educacional brasileiro}

A formação de professores de música no Brasil será objeto de reflexões neste texto a partir de 1996, com a aprovação da Lei n. 9394, a Lei de Diretrizes e Bases da Educação Nacional - LDB (BRASIL, 1996). Diversos indicadores foram estabelecidos para a educação brasileira prevendo a atuação e a normatização de procedimentos específicos a serem realizadas pela União, Estados e municípios, garantindo liberdade e autonomia aos sistemas educacionais na organização de seus projetos pedagógicos. Isso significa que é possível encontrar diferentes perspectivas e abordagens educacionais nas escolas brasileiras, tanto em nível de Educação Básica (de 0 a 17 anos aproximadamente) quanto da Educação Superior (cursos universitários de graduação e pós-graduação), que preparam tambem profissionais da educação.

A Educação Básica é dividida em três níveis: Educação Infantil (de 0 a 5 anos), Ensino Fundamental (de 6 a 14 anos) e Ensino Médio (de 15 a 17 anos). Os professores que atuam nestes níveis devem possuir formação em curso superior de licenciatura plena (BRASIL, 1996, art. 62), sendo esta a modalidade de curso superior no Brasil que forma professores nas diferentes áreas curriculares. Assim, a licenciatura em música seria, logicamente, a formação necessária para aqueles que desejam ser professores de música na escola brasileira. No entanto, esta lógica não é aplicável em todos os sistemas educacionais, nem para a área de música, nem para outras áreas do currículo. A falta de professores em diversos contextos faz com que pessoas habilitadas em uma determinada área atuem em outra área suprindo as demandas das escolas.

A recente aprovação da Lei n. 11769/2008 (BRASIL, 2008), que trata da música como conteúdo obrigatório na escola brasileira, tem gerado diversos questionamentos sobre sua aplicação efetiva nas escolas brasileiras. A atuação polivalente de um único professor responsável por todas as áreas das artes na 
escola, licenciado em educação artística - antiga diplomação -, é ainda muito presente no cenário brasileiro, o que tem contribuído para a ausência significativa da música no currículo escolar (FIGUEIREDO, 2004, 2010). Os professores de música têm preferido a atuação em espaços educativos diferentes da escola regular por razões várias, incluindo melhores salários e condições de trabalho. Como afirma Penna (2010), de forma especial "na rede pública, as dificuldades da escola básica para a educação musical são reais - turmas grandes, falta de condições materiais, baixos salários, desvalorização do professor, indisciplina ou violência, etc." (p. 151), o que certamente tem influenciado na motivação dos estudantes de licenciatura pela não escolha da escola regular como campo de atuação.

Os espaços para professores nas escolas públicas brasileiras dependem de concursos e processo de seleção. Ainda hoje, editais solicitam profissionais licenciados em educação artística, preferindo o modelo polivalente para o ensino de artes na escola. A precariedade deste modelo, a superficialidade e a consequente desvalorização das áreas de artes no currículo têm sido discutidos há vários anos por especialistas das áreas de artes, mas parece que tal discussão ainda não atingiu efetivamente diversos sistemas educacionais. A legislação atual que regulamenta a formação de professores no Brasil não inclui mais a licenciatura em educação artística, sendo que cada uma das linguagens possui orientações específicas na legislação (BRASIL, 2004a, 2004b, 2004c, 2009). Hoje na escola brasileira ainda atuam diversos profissionais com a formação polivalente da educação artística, situação que tende a mudar com o tempo, medida que os novos profissionais nas áreas de artes serão licenciados em áreas específicas.

\section{Documentos oficiais e a formação de professores no Brasil}

Três documentos oficiais serão considerados para a breve discussão aqui apresentada: Diretrizes Curriculares Nacionais para a Formação de Professores da Educação Básica (BRASIL, 2002a), Resolução CNE/CP n. 2 que institui a duração e a carga horária dos cursos de licenciatura (BRASIL, 2002b) e Diretrizes Curriculares Nacionais para os Cursos de Graduação em Música (BRASIL, 2004a). Estes documentos complementam-se na medida em que os dois primeiros têm caráter geral, são dirigidos para todas as áreas de formação de professores, e o terceiro é específico para a área de música, sendo direcionado tanto para o bacharelado quanto para a licenciatura.

A autonomia das instituições formadoras está garantida desde 1996 com a Lei n. 9394 e é reforçada pelas Diretrizes Curriculares Nacionais:

III - as instituições constituirão direção e colegiados próprios, que formulem seus próprios projetos pedagógicos, articulem as unidades acadêmicas envolvidas e, a partir do projeto, tomem as decisões sobre organização institucional e sobre as questões administrativas no âmbito de suas competências. (BRASIL, 2002a, Art. 17) 


\section{Graça Mota - Sergio Figueiredo}

A carga horária é estabelecida pela Resolução CNE/CP n. 2 (BRASIL, 2002b) com relação aos diferentes componentes desta formação universitária: mínimo de 2800 horas no total do curso,

I - 400 (quatrocentas) horas de prática como componente curricular;

II - 400 (quatrocentas) horas de estágio curricular supervisionado;

III - 1800 (mil e oitocentas) horas de aulas para os conteúdos curriculares de natureza científicocultural;

IV - 200 (duzentas) horas para outras formas de atividades acadêmico-científico-culturais. (BRASIL, 2002b, Art. 1)

Questões específicas da formação em música estão indicadas nas Diretrizes para os cursos de música, definindo conteúdos a serem inseridos nos currículos:

I - conteúdos básicos: estudos relacionados com a Cultura e as Artes, envolvendo também as Ciências Humanas e Sociais, com ênfase em Antropologia e Psico-pedagogia;

II - conteúdos específicos: estudos que particularizam e dão consistência à área de Música, abrangendo os relacionados com o Conhecimento Instrumental, Composicional, Estético e de Regência;

III - conteúdos teórico-práticos: estudos que permitam a integração teoria/prática relacionada com o exercício da arte musical e do desempenho profissional, incluindo também Estágio Curricular Supervisionado, Prática de Ensino, Iniciação Científica e utilização de novas tecnologias. (BRASIL, 2004a, Art. 5)

Os documentos norteadores da educação brasileira apresentam, em muitos casos, orientações gerais, permitindo diversas interpretações e adaptações aos diversos contextos educativos. Tal flexibilidade garante a autonomia estabelecida pela legislação e pode ser fator positivo para o estabelecimento de currículos que formam professores de música. Isso quer dizer que diferentes perspectivas convivem neste processo de formação de professores de música, dependendo da instituição, dos professores que nela atuam, das concepções de música e de educação que podem adquirir distintos formatos. Assim, a definição de áreas e carga horária para a formação pedagógica e para a formação musical possibilitam diversos encaminhamentos sobre como este processo será desenvolvido para garantir qualidade e eficiência na formação oferecida nas licenciaturas. 


\section{Testes de seleção para o ingresso nas universidades brasileiras}

Um dos elementos a ser considerado na formação de professores refere-se ao ponto de partida do currículo na universidade. Deve-se considerar que os alunos já apresentam algum tipo de formação musical antes da universidade ou os mesmos poderiam começar tal aprendizado ao ingressarem na licenciatura?

Dois pontos relevantes podem ser trazidos com relação a esta questão. O primeiro é de ordem social, em que a perspectiva da inclusão seria considerada estabelecendo que todas as pessoas deveriam ter o direito a cursarem uma licenciatura em música. Ao se exigir formação musical para a realização do teste específico estaria se estabelecendo uma exclusão daqueles que não tiveram tal formação na escola, nem puderam pagar pela formação musical em instituições, normalmente privadas. Cabe ressaltar que no Brasil a existência de escolas de música públicas é muito rara e poucos podem frequentar este tipo de estabelecimento. Assumindo esta perspectiva, o teste específico enfatizaria a exclusão.

O segundo ponto a ser considerado com relação ao teste de ingresso nas universidades está relacionado com a preparação irregular, ou inexistente, de música ao longo da Educação Básica. Associa-se a este fato, portanto, que a formação musical pode ser realizada das mais diversas formas, com conteúdos muito diversificados. Assim é comum que os alunos que ingressam em um licenciatura possuam conhecimentos musicais diversos, o que dificulta o estabelecimento de um currículo que efetivamente contemple a todos no processo de formação de professores. Nesta perspectiva, seria desejável o teste de ingresso, que buscaria, entre outros elementos, estabelecer parâmetros para a seleção dos candidatos que estariam aptos a frequentar o curso previamente estabelecido. Cabe destacar que a maioria das instituições brasileiras (72\%) realiza teste específico de música para o ingresso em suas licenciaturas (FIGUEIREDO; SOARES, 2009; 2010).

\section{Questões de prática pedagógica na formação de professores no Brasil}

A preparação para a atuação docente se faz a partir das reflexões teóricas do campo da educação e através das experiências práticas que são oferecidas nos cursos de licenciatura em música no Brasil, incluindo obrigatoriamente o estágio docente. Os documentos anteriormente citados tratam desta matéria orientando a prática pedagógica exigida para a licenciatura. A prática como componente a ser desenvolvido na formação de professores é enfatizada na legislação:

Art. 12. A prática, na matriz curricular, não poderá ficar reduzida a um espaço isolado, que a restrinja ao estágio, desarticulado do restante do curso. 
§ 1 A prática deverá estar presente desde o início do curso e permear toda a formação do professor.

$\S 2^{\circ}$ No interior das áreas ou das disciplinas que constituírem os componentes curriculares de formação, e não apenas nas disciplinas pedagógicas, todas terão a sua dimensão prática. (BRASIL, 2002a)

O mesmo texto legal trata dos estágios curriculares supervisionados, que devem ser realizados "a partir do início da segunda metade do curso" (BRASIL, 2002a) em escolas de Educação Básica. Outro documento já mencionado define " 400 horas de prática como componente curricular" e " 400 horas de estágio curricular supervisionado" (BRASIL, 2002b).

As Diretrizes específicas para a graduação em música destacam que o estágio curricular deve ser "direcionado à consolidação dos desempenhos profissionais desejados, inerentes ao perfil do formando" (BRASIL, 2004a). Esta abertura para "desempenhos profissionais desejados" contempla diversos espaços educacionais além da escola regular, trazendo para os cursos de licenciatura uma outra responsabilidade em termos formativos. Atividades musicais ocorrem em variados espaços sociais, com características distintas, o que solicita preparação também distinta em termos de formação de professores.

\section{Perspectivas profissionais no Brasil}

Com a nova legislação de 2008 espera-se uma ampliação significativa das vagas para professores de música na Educação Básica brasileira. No entanto, é preciso superar diversos desafios, sendo que alguns deles foram brevemente apresentados neste texto. As concepções de ensino de arte e de música nas escolas precisam ser revistas em diversos contextos para que se estabeleça um projeto pedagógico no qual a música esteja presente. As mudanças de concepção implicam também espaços para o desenvolvimento das atividades musicais, o que significa mudanças curriculares, reorganização de carga horária, aquisição de materiais, dentre outros aspectos.

Uma situação preocupante é a motivação para a atuação na Educação Básica brasileira. Resultados da pesquisa intitulada "A formação do professor de música no Brasil", desenvolvida pelo Grupo de Pesquisa "Música e Educação", da Universidade do Estado de Santa Catarina (Udesc), mostram que um número reduzido de estudantes de licenciatura em música sente-se motivado a atuar na Educação Básica. A pesquisa coletou dados em 79 cursos que oferecem cursos de licenciatura em música (FIGUEIREDO; SOARES, 2010). Dos 1924 estudantes participantes da pesquisa, apenas $28 \%$ desejam atuar na escola de Educação Básica. Este resultado aponta para um grande desafio a ser vencido, já que os cursos de licenciatura estão formando professores de música que não pretendem, em grande parte, ministrarem aulas na Educação Básica. Ao mesmo tempo em que se trabalha para conquistar mais vagas para professores de música, com concursos específicos para esta área, é preciso construir 
o interesse de mais licenciados em música para a atuação na escola regular, promovendo efetivamente a presença da educação musical na escola brasileira.

\section{Discussão}

Considerando os elementos destacados sobre a formação de professores em Portugal e no Brasil é possível estabelecer comparações com o objetivo de ampliar as reflexões sobre esta temática. As diferenças dos sistemas educacionais investigados não impedem que se discutam perspectivas que visam, em última instância, preparar professores de música para a escola regular. As peculiaridades de cada sistema são resolvidas no âmbito de cada contexto educativo, mas algumas ideias gerais podem ser destacadas.

\section{Sobre as provas de ingresso (Portugal e Brasil)}

Sobre a prova de ingresso para os cursos que formam professores de música em ambos os países, parece haver um entendimento da necessidade desta avaliação prévia daqueles que desejam ingressar no curso que forma professores de música. Em Portugal há ofertas de preparação específica em conservatórios e academias de música com subsídios públicos, além da disciplina educação musical estar presente no currículo do Ensino Básico. No Brasil, são poucos os espaços públicos de preparação musical anterior à universidade, a formação musical não está garantida nos currículos escolares de um modo geral, o que estabelece certa elitização nos processos de seleção para os que desejam cursar uma licenciatura em música, já que tais conhecimentos específicos deveriam ser adquiridos em espaços privados, não acessíveis a toda a população. Neutralizando a questão da elitização, parece haver uma clareza de intenção do teste específico, no qual se estabelecem pré-requisitos para os que desejam frequentar um curso superior de música. Em Portugal, estes testes em nada se assemelham aos de entrada para uma licenciatura em instrumento, composição ou canto, priviligiando sobretudo um perfil de potencialidades. Entende-se por isto um enfoque em competências musicais que podem ter sido adquiridas em contextos diversificados, desde as academias e conservatórios públicos ou privados aos grupos de prática musical com carácter mais ou menos informal, considerando-se que ambos os contextos deverão ser potenciadores de um desenvolvimento futuro em contexto acadêmico. Da mesma forma, no Brasil, as provas de ingresso para os cursos de bacharelado diferenciam-se das provas da licenciatura em música pela ênfase na execução musical. A forma e os conteúdos de tais testes seletivos evidentemente poderiam ser discutidos e este seria assunto para outro texto. Em todo o caso, os testes de seleção, de alguma forma, indicam que a formação em nível superior não é introdutória, ou seja, aqueles que desejam ser professores de música já deveriam possuir conhecimentos específicos para, na universidade, aprofundá-los e conectá-los com os diversos componentes, pedagogia musical. 


\section{Graça Mota - Sergio Figueiredo}

\section{Sobre a prática pedagógica (Portugal e Brasil)}

A relevância da prática pedagógica é indiscutível para a formação do professor de música em ambos os contextos educacionais observados. Com diferentes formatos, questões musicais e pedagógicas permeiam a formação do professor de música. No Brasil, as questões práticas devem estar presentes durante todo o curso, e os estágios devem ser realizados na segunda metade da licenciatura. Em Portugal, algumas abordagens pedagógicas em contextos não formais e informais já estão contempladas na licenciatura, sendo que a prática de estágio efetivamente acontece no mestrado profissionalizante que prepara os professores para o Ensino Básico.

As licenciaturas brasileiras possuem, em geral, 4 anos, e representam o requisito mínimo para a atuação na Educação Básica. Em Portugal, a licenciatura possui 3 anos, mas para ser professor do Ensino Básico é preciso ter cursado o mestrado profissionalizante, que aprofunda as questões específicas sobre a prática de ensino na escola. Há semelhanças entre os dois sistemas na medida em que a prática e o estágio são contemplados nesta formação de professores, atendendo a diferentes especificidades necessárias para o exercício profissional. Cabe destacar a perspectiva do mestrado profissionalizante no contexto europeu a partir da declaração de Bolonha e que, ao abranger também os Educadores de Infância, se traduz num processo de homogeneização e dignificação de todos os profissionais que trabalham em educação, independentemente do nível etário. Por outro lado, é de realçar que o fato de se tratar de um grau profissionalizante inviabiliza a realização de um trabalho com maior relevância ao nível da investigação, já que o grande enfoque acadêmico se situa ao nível do relatório final referente às práticas educativas.

No Brasil, a pós-graduação em nível de mestrado e doutorado está também disponível para os professores das escolas de Educação Básica, mas tal titulação não é condição para o trabalho na escola. Ter o título de mestre ou doutor pode significar um incremento na carreira do professor, dependendo do sistema educacional. Mas não são oferecidos mestrados profissionalizantes na área de música no Brasil.

\section{Sobre as perspectivas futuras (Portugal e Brasil)}

Com relação ao futuro profissional vislumbrado a partir dos cursos de formação de professores nos dois países aqui tratados, evidenciam-se o interesse e o desejo dos alunos pela atuação no Ensino Básico em Portugal, diferentemente da falta de motivação dos estudantes brasileiros para a atuação na Educação Básica no Brasil. As regularidades da oferta da educação musical como componente curricular autônomo nas escolas e as condições de trabalho e de salário parecem ser elementos motivadores para os futuros professores de música em Portugal, ao contrário do Brasil onde ainda se luta pela inclusão da música como conteúdo efetivo do currículo, ministrada por profissionais especializados, nos diversos sistemas educacionais. 


\section{Considerações finais}

Os resultados preliminares desta análise comparativa demonstram semelhanças e diferenças na formação de professores de música em Portugal e no Brasil, o que já era esperado, já que os dados se referem a contextos distintos. Os resultados são considerados preliminares, pois o presente estudo pretende aprofundar estas e outras questões relativas à formação de professores de música.

A partir desta análise preliminar, é possível sintetizar os seguintes pontos:

1) professores de música para a educação escolar são formados em instituições de ensino superior nos dois países, sendo que em Portugal, alem da licenciatura em música, é exigida a formação em nível de mestrado profissionalizante, totalizando 5 anos de formação, contra aproximadamente 4 anos praticados normalmente no Brasil;

2) em ambos os países são realizadas provas específicas de ingresso nas universidades, exigindo conhecimentos musicais prévios dos estudantes, o que poderia estimular um debate sobre as funções destas provas e seus conteúdos;

3) o equilíbrio entre a formação musical e pedagógica é um dos objetivos curriculares e em ambos os países são oferecidas disciplinas específicas e experiências curriculares que pretendem formar adequadamente um profissional para a educação musical;

4) a prática docente é componente enfatizado na formação de professores, com diferentes formatos, mas evidenciando a importância do contato e da prática com o ambiente escolar;

5) em Portugal, a motivação para a atuação na escola regular é maior do que no Brasil, e a procura pelos cursos de mestrado profissionalizante tem demonstrado este interesse; contrariamente, no Brasil, um dos grandes desafios é exatamente a motivação e a presença de mais educadores musicais habilitados nas escolas.

Finalizando, este estudo pretende aprofundar estas e outras questões sobre a formação de professores de música em Portugal e no Brasil. O aprofundamento das análises, o exercício comparativo e a reflexão sobre tópicos de interesse para a formação de professores de música poderão contribuir para o debate desta área tão complexa e tão relevante para o desenvolvimento das práticas de educação musical em diferentes contextos.

\section{Referências}

BRASIL. Lei n. 9394/96 - Lei de Diretrizes e Bases da Educação Nacional. Brasília: Ministério da Educação, 1996. Disponível em: <http://portal.mec.gov.br/ seed/arquivos/pdf/tvescola/leis/lein9394.pdf>. Acesso em: 15 fev. 2012. 


\section{Graça Mota - Sergio Figueiredo}

BRASIL. Resolução CNE/CP n. 1, de 18 de fevereiro de 2002 (Institui Diretrizes Curriculares Nacionais para a Formação de Professores da Educação Básica, em nível superior, curso de licenciatura, de graduação plena). Brasília: Conselho Nacional de Educação/Conselho Pleno - CNE/CP, 2002a. Disponível em: http:/ /portal.mec.gov.br/cne/arquivos/pdf/CP012002.pdf. Acesso em: 15 fev. 2012.

Resolução CNE/CP n. 2, de 19 de fevereiro de 2002. (Institui a duração e a carga horária dos cursos de licenciatura, de graduação plena, de formação de professores da Educação Básica em nível superior). Brasília: Conselho Nacional de Educação/Conselho Pleno - CNE/CP, 2002b. Disponível em: <http:// portal.mec.gov.br/cne/arquivos/pdf/ CP022002.pdf>. Acesso em: 15 fev. 2012.

Resolução n. 2, de 8 de março de 2004. Aprova as Diretrizes Curriculares Nacionais do Curso de Graduação em Música e dá outras providências. Brasília: Conselho Nacional de Educação/Câmara de Educação Superior - CNE/CES, 2004a. Disponível em: http://portal.mec.gov.br/cne/arquivos/pdf/CES02-04.pdf. Acesso em: 15 fev. 2012.

Resolução n. 3, de 8 de março de 2004. Aprova as Diretrizes Curriculares Nacionais do Curso de Graduação em Dança e dá outras providências. Brasília: Conselho Nacional de Educação/Câmara de Educação Superior - CNE/CES, 2004b. Disponível em: http://portal.mec.gov.br/cne/arquivos/pdf/CES03-04.pdf. Acesso em: 15 fev. 2012.

Resolução n. 4, de 8 de março de 2004. Aprova as Diretrizes Curriculares Nacionais do Curso de Graduação em Teatro e dá outras providências. Brasília: Conselho Nacional de Educação/Câmara de Educação Superior - CNE/CES, 2004c. Disponível em: http://portal.mec.gov.br/cne/arquivos/pdf/CES04-04.pdf. Acesso em: 15 fev. 2012.

Lei n. 11.769/08. Altera a Lei no 9.394, de 20 de dezembro de 1996, Lei de Diretrizes e Bases da Educação, para dispor sobre a obrigatoriedade do ensino da música na Educação Básica. Brasília: Presidência da República, 2008. Disponível em: http://www.planalto.gov.br/ccivil_03/_Ato2007-2010/2008/ Lei/L11769.htm. Acesso em: 15 fev. 2012.

Resolução n. 1, de 16 de janeiro de 2009. Aprova as Diretrizes Curriculares Nacionais do Curso de Graduação em Artes Visuais e dá outras providências. Brasília: Conselho Nacional de Educação/Câmara de Educação Superior - CNE/CES, 2009. Disponível em: http://portal.mec.gov.br/cne/arquivos/pdf/2009/rces001_09.pdf. Acesso em: 15 fev. 2012.

DECLARAÇÃO DE BOLONHA. O processo de Bolonha. Lisboa: Direção Geral do Ensino Superior, 1999. Disponível em: <http://www.dges.mctes.pt/DGES/ pt/Estudantes/Processo+de+Bolonha/Processo+de+Bolonha/>. Acesso em: 27 fev. 2012.

FERREIRA, A. G. O sentido da Educação Comparada: Uma compreensão sobre a construção de uma identidade. Educação, Porto Alegre, v. 31, n. 2, p. 
124-138, maio/ago. 2008. http://revistaseletronicas.pucrs.br/ojs/index.php/faced/ article/viewFile/2764/2111. Acesso em: 31 jan. 2012.

FIGUEIREDO, S. L. F. A preparação musical de professores generalistas no Brasil. Revista da ABEM. Porto Alegre, v. 11, p. 55-62, 2004.

Educación musical en la escuela brasilena: aspectos históricos, legislación educacional y desafios contemporâneos. Revista Musical Chilena, Santiago, Chile, vol. 214, p. 36-51, 2010. Disponível em: <http://www.scielo.cl/ $\mathrm{scielo}$. php? s cript=s ci_art text \& pid=S 0716 $27902010000200005 \&$ lng=es\&nrm=iso $>$. Acesso em: 15 fev. 2012.

FIGUEIREDO, S. L. F.; SOARES, J . A formação do professor de música no Brasil: Ações do Grupo de Pesquisa MUSE - Música e Educação.In: CONGRESSO DA ABEM, 18 e SIMPÓSIO PARANAENSE DE EDUCAÇÃO MUSICAL, 15, 2009, Londrina. Anais... Londrina: ABEM, 2009, p. 170-178. Disponível em: <http://www.abemeducacaomusical.org.br/Masters/ anais2009/ anais_abem_2009.pdf>.Acesso em: 20 jan. 2012.

A formação do professor de música no Brasil: desafios metodológicos. In: CONGRESSO ANUAL DA ASSOCIAÇÃO BRASILEIRA DE EDUCAÇÃO MUSICAL, 19, Goiânia. Anais... Goiânia: ABEM, 2010, p. 187-196. Disponível em: <http://www.abemeducacaomusical.org.br/ Masters/anais2010/ Anais_abem_2010.pdf $>$. Acesso em: 20 jan. 2012.

MARCONDES, M. A. S. Educação Comparada: perspectivas e investigações. EccoS, São Paulo, v. 7, n. I, p. 139 -163, 2005. Disponível em: <http:// redalyc.uaemex.mx/pdf/715/ 71570107.pdf>. Acesso em: 15 jan. 2012.

MOTA, G. Portugal. In: D. J. HARGREAVES; A. C. NORTH (Eds.), Musical development and learning: The international perspective. p. 151-162. London: Continuum, 2001.

. A formação para a expressão musical na educação de infância e no $1^{\circ}$ ciclo do ensino básico: contributo para um olhar crítico. Educare Apprendere, Lisboa, 1, p. 23-37, 2003.

A música no $1^{\circ}$ ciclo do ensino básico: Contributo para uma reflexão sobre o conceito de enriquecimento curricular. Revista de Educação Musical, Associação Portuguesa de Educação Musical APEM, Lisboa, Vol. 128 -129, p. 16-21, 2007.

NÓVOA, A.; CATANI, D. B. Estudos comparados sobre a escola: Portugal e Brasil (séculos XIX e XX). Rio de Janeiro: Texto aprovado para ser apresentado no I Congresso Brasileiro de História da Educação, novembro de 2000. Disponível em: http://www.sbhe.org.br/novo/congressos/cbhe1/anais/ 028_antonio_denice.pdf. Acesso em: 2 fev. 2012.

PENNA, M. Música(s) e seu ensino. 2. ed. rev. ampl. Porto Alegre: Sulina, 2010. 
Graça Mota - Sergio Figueiredo

PORTUGAL. Decreto-Lei no 310/83 (Reestrutura o ensino da música, dança, teatro e cinema). Lisboa: Ministérios das Finanças e do Plano, da Educação e da Reforma Administrativa, 1983. Disponível em: <http://www.dre.pt/cgi/ dr1s.exe? $\mathrm{t}=\mathrm{dr} \& \mathrm{cap}=1-1200 \& \mathrm{doc}=19832274 \% 20 \& \mathrm{v} 02=\& \mathrm{v} 01=2 \& \mathrm{v} 03=1900-01-$ $01 \& v 04=3000-12-21 \& v 05=\& v 06=\& v 07=\& v 08=\& v 09=\& v 10=\& v 11=\% 27$ DecretoLei\%27\&v12=\&v13=\&v14=\&v15=\&sort=0\&submit=Pesquisar $>$. Acesso em: 26 fev. 2012.

PORTUGAL. Lei de Bases do Sistema Educativo, Lei n. 46/86. (Estabelece o quadro geral do sistema educativo português). Lisboa: Diário da República, 1986. Disponível em: http://www.sg.min-edu.pt/pt/informacao-do-sistemaeducativo/legislacao-e-regulamentacao-da-educacao/lei-de-bases-do-sistemaeducativo/ . Acesso em: 26 fev. 2012.

. Decreto-Lei n. 74/2006 de 24 de março (Regulamenta as alterações introduzidas pela Lei de Bases do Sistema Educativo relativas ao novo modelo de organização do ensino superior). Lisboa: Ministério da Ciência, Tecnologia e Ensino Superior, 2006. Disponível em: <http://www.dges.mctes.pt/DGES/pt/ Geral/MenuTopo/Legislacao/Grau+Titulos +Equivalencias.htm>. Acesso em: 27 fev. 2012.

Decreto-Lei n. 43/2007 de 22 de fevereiro. (Aprova o regime jurídico da habilitação profissional para a docência na educação pré-escolar e nos ensinos básico e secundário). Lisboa: Ministério da Ciência, Tecnologia e Ensino Superior, 2007.Disponível em: http://www.dges.mctes.pt/DGES/pt/Geral/ MenuTopo/Legislacao/Formação+em+Áreas+Específicas.htm. Acesso em: 27 fev. 2012.

\section{Correspondência}

Graça Mota - Rua Dr. Roberto Frias, 602, CEP 4200-465, Porto, Portugal.

Sergio Figueiredo - Rua das Araras, 277, Florianópolis, SC, CEP 88062-075.

E-mail: gmota@ese.ipp.pt - sergiofigueiredo.udesc@gmail.com 